\title{
Effectiveness of the Planned Teaching Program on Deep Vein Thrombosis among the Staff Nurses of selected hospital.
}

\author{
Prof Sasmita Das ${ }^{1}$, Anjali Sahoo ${ }^{2}$, Rasmita swain ${ }^{2}$ \\ 1)Associate Dean.SUM Nursing college,SOA university, Bhubaneswar \\ 2)Nursing Supervisor, SUM Hospital, Bhubaneswar. \\ 3),Infection control Nurse, SUM Hospital, Bhubaneswar.
}

\begin{abstract}
Deep vein thrombosis (DVT) is still an underestimated complication in trauma patients. Only 10 percent of individuals who require DVT prophylaxis receive it; the remaining 90 percent of individuals are deprived of DVT prophylaxis because of ignorance and lack of awareness. Deep vein thrombosis is a serious condition with potentially fatal consequences. Many patients in both hospital and the community are at increased risk of DVT, and it is therefore important for nurses to understand the condition and how to recognize it. The purpose of the study is to determine the effectiveness of Planned Teaching Program on DVT among the Staff Nurses. An exclusive review of related literature helped in preparation of data collection tools to assess the knowledge on DVT among the staff nurses. Therefore a questionnaire with the aid of a well formulated interview schedule was used to collect data from 60 staff nurses in SUM Hospital, BBSR. There was a positive correlation between the pre test \& post test knowledge of staff nurses in which ' $r$ ' value is $0.14 \%$ at $90 \%$ level of significance. There was a significant difference between the mean pre-test and post-test knowledge scores in which ' $\boldsymbol{t}$ ' is 21.8 with a mean difference 2.6 of nurses regarding D.V.T \& thus the planned teaching program was effective. it can be concluded that there is a need to increase the awareness of DVT, individual's risk factors and triggering events so that we can reduce the number of patients that die every year from DVT and its complications.
\end{abstract}

Key words: Effectiveness, Planned Teaching Program, Deep Vein thrombosis, Staff Nurses.

\section{Introduction}

Every hospitalized patient is at risk for a thromboembolic complication. Deep vein thrombosis is a silent killer (Autar 1996a). It is a serious threat to recovery from surgery and is the third most common vascular disease, after ischemic heart disease and stroke (Anands et al. 1998, Turpie 1997).Deep vein thrombosis (DVT) is a precursor of potentially fatal pulmonary embolism (PE). About $79 \%$ of patients who present with pulmonary embolism have evidence of deep vein thrombosis in their legs. About half patients with pelvic vein thrombosis or proximal leg DVT develop PE, which is usually asymptomatic. If it is left untreated, one of the most severe complications of a DVT is a pulmonary embolism(PE), defined as "presence of a blood clot in a pulmonary arterial blood vessel that obstructs circulation to lung tissue" (Tortora \& Derrickson, 2006, p. G29). Symptoms of pulmonary emboli may include dyspnea, pleuritic pain, heart palpitations, hemoptysis, and a feeling of anxiousness (Goldman \& Ausiello, 2008).

DVT is the most common type of venous thrombosis. However, venous thrombosis can form anywhere in the venous system. If a part or all of the blood clot in the vein breaks off from the site where it is formed, it can travel through the venous system; this is called an embolus. If the embolus lodges in the lung, it is called pulmonary embolism (PE), a serious condition that leads to over 50,000 deaths a year in the United States. Deep vein thrombosis (DVT) of the lower limbs and pulmonary embolism (PE) continue to be significant causes of post-operative morbidity and mortality (Collier, 1999). A 2002 survey from the American Public Health Association found that $74 \%$ of U.S. adults knew little or nothing about DVT. This is an alarming number, considering every year 2 million people get deep vein thrombosis and up to 200,000 of them die from it. Deep vein thrombosis is a serious condition with potentially fatal consequences. Many patients in both hospital and the community are at increased risk of DVT, and it is therefore important for nurses to understand the condition and how to recognize it.

So the overall aim of the study was to find out the effectiveness of planned teaching programme in Deep Vein Thrombosis among the staff nurses.

\section{Back ground}

According to George et al. (2010), a quantitative, cross section server design was used and 48 participants receiving pharmacological thromboprophylaxis participated. Most hospitalized patients (83\%) were aware that were receiving injections to prevent blessed lots and $81.2 \%$ reposted hearing of either DVT, PE are 
both conditions of the patients who had heard of DVT and/or PE, 74.2\% knew immobility was a risk factor but had limited knowledge of symptoms and prevention modalities. Participants reported hearing about VTE more frequently form friends, family or media than form health care providers, including nurses, participants were satisfied with pharmacological thrombo prophylaxis but were less satisfied with the information received on VTE. Findings suggest that patients require further information on VTE during their hospitalization to enhance their involvement in VTE prevention and recognition and that the provision of written, patient directed information could begin to address that lack of involvement. This study also highlights the need to strengthen the nurse's role in providing patient education about VTE.

According to Surendra et al. (2009), deep vein thrombosis (DVT) institutes a serious threat to patient's general recovery. The Autor DVT risk assessment scale was developed to separate risk categories founded in Virchow's traid in the genesis of DVT, the scale is composed of seven categories of risk factors. When the scale was tested on a trauma/orthopedics unit a cut-off score of 16 yielded $100 \%$ sensitivity, $81 \%$ specificity and a correlation coefficient of 0.98 . The DVT scale is designed to allow application in diverse clinical specialties. It is recommended that staff nurses using the Author DVT scale should evaluate for themselves the best cut-off score to achieve maximum predictive accuracy.

Markel (1992), deep vein thrombosis is a disorder frequently affecting the DVT of the lower limbs, its onset is included by know risk factors. The main complications of DVT are pulmonary embolism and post thrombotic syndrome (PST). DVT is associated with a mortality rate of $11-23 \%$. If not treated this is the cause of increased morbidity and disability. In a recent study by Markel et al. (1992), 110 patients (126 legs) with DVT were prospectively followed using duplex during the cause of 5 consecutive years.

\section{Objectives}

- To assess the knowledge on Deep Vein Thrombosis among the staff nurses before \& after administration of planned teaching programme.

- To find out the effectiveness of Planned Teaching Programme on knowledge of Staff Nurses in Deep Vein Thrombosis.

- To find out the correlation between pre test and post test knowledge on deep vein thrombosis.

\section{Materials and Methods}

The research design was one group pre test and post test design with evaluative research approach. Sixty staff nurses working in various wards of SUM hospital, Bhubaneswar were selected by non probability purposive sampling. The study comprised a documentation of systematic investigations on demographic status of the families \& knowledge of staff nurses on DVT by using a well formulated interview schedule. The "questionnaire on knowledge aspect on deep vein thrombosis among the staff nurses" was used for data collection. For Ethical consideration, permission was taken from ethical committee \& an informed consent obtained from the staff nurses indicating their willingness to participate in the study. The tool was validated on clarity and the appropriateness of the items, by giving it to different experts. The internal consistency of the tool was tested by crohnbach $\alpha$ test .which was $0.84 \&$ it was reliable. Pretest was done, Planned teaching program on DVT was given to the staff nurses \& The staff nurses response was evaluated after $5^{\text {th }}$ day of planned teaching program .All the data pertaining to the knowledge of staff nurse regarding deep vein thrombosis after collecting was processed and analyzed using statistical tools like Karl Pearson's Coefficient of Correlation and, ,te- test.

\section{Results \& findings}

Distribution of the study subjects according to socio-demographic variable

Six percent of the staff nurses, were in the age group of above 22 years, $16.2 \%$ were in the age group of 23 25 years. $19.8 \%$ of staff nurse have more than 2 year experience and $1.2 \%$ have experience between $5-10$ years.According to educational status of staff nurse in which $13.8 \%$ are from science, $6.6 \%$ from arts. $72 \%$ of staff nurses have attended the educational program on Deep Vein Thrombosis \& 9.0\% of staff nurses had not attended the educational program. On the basis of professional qualification of staff nurses in which $6.6 \%$ are from Basic B.Sc nursing, 3.0\% from P.B. B.Sc nursing, $15.6 \%$ were from GNM.

Knowledge on Deep Vein Thrombosis among the staff nurses before \& after administration of planned teaching programme

Item wise analysis of pre-test and post-test percentage score of the subject related to the knowledge aspects of staff nurse on deep vein thrombosis $(N-60)$. 


\begin{tabular}{|l|l|l|l|l|l|}
\hline S.L. & Question & Pre-test & Post-test \\
\cline { 3 - 6 } No. & Frequency & Percentage & Frequency & Percentage \\
\hline Q1 & Clot formation in blood vessel is called DVT. & 15 & 25 & 38 & 63 \\
\hline Q2 & $\begin{array}{l}\text { Prolonged hospitalization is the most common } \\
\text { cause of DVT. }\end{array}$ & 14 & 20 & 45 & 75 \\
\hline Q3 & $\begin{array}{l}\text { Anti-thrombin deficiency is the most common } \\
\text { inherited cause of DVT. }\end{array}$ & 12 & 15 & 39 & 65 \\
\hline Q4 & $\begin{array}{l}\text { Immobilization is the most acquired cause of } \\
\text { DVT. }\end{array}$ & 14 & 20 & 34 & 56 \\
\hline Q5 & $\begin{array}{l}\text { Redness and discolouration of skin is sign and } \\
\text { symptom of DVT. }\end{array}$ & 15 & 25 & 46 & 76 \\
\hline Q6 & Chest pain and palpitation is the symptom of PE. & 10 & 10 & 38 & 63 \\
\hline Q7 & Femoral vein is the possible site of the DVT. & 14 & 20 & 36 & 60 \\
\hline Q8 & $\begin{array}{l}\text { Recorrent DVT and PE are the long term affect of } \\
\text { DVT. }\end{array}$ & 14 & 20 & 38 & 63 \\
\hline Q9 & $\begin{array}{l}\text { Red blood cell and fibrin is the main component } \\
\text { of several venous thrombosis. }\end{array}$ & 13 & 21 & 40 & 66 \\
\hline Q10 & $\begin{array}{l}\text { Venous Doppler ultrasound is common } \\
\text { investigation for diagnosed DVT. }\end{array}$ & 30 & 50 & 50 & 83 \\
\hline Q11 & $\begin{array}{l}\text { Doppler analysis is the Radiological test } \\
\text { conducted for DVT. }\end{array}$ & 26 & 43 & 54 & 90 \\
\hline Q12 & Prolonged bed rest is the risk factor of DVT. & 24 & 40 & 56 & 93 \\
\hline Q13 & PE is the life threatening complication of DVT. & 34 & 56 & 57 & 95 \\
\hline Q14 & $\begin{array}{l}\text { The blood vessel wall will be damaged in arterial } \\
\text { and venous thrombosis. }\end{array}$ & 38 & 63 & 54 & 90 \\
\hline Q15 & $\begin{array}{l}\text { Compression stocking is the purpose of using } \\
\text { elastic stocking in DVT. }\end{array}$ & 40 & 66 & 59 & 98 \\
\hline Q16 & DVT stocking is the common DVT prophylaxis. & 43 & 71 & 54 & 90 \\
\hline Q17 & $\begin{array}{l}\text { DVT can occur in case of pregnant women in } \\
\text { sometimes. }\end{array}$ & 40 & 66 & 49 & 81 \\
\hline Q18 & Anticoagulants are the blood thinning medication. & 38 & 63 & 50 & 83 \\
\hline Q19 & $\begin{array}{l}\text { Ambulation is the main nursing responsibility on } \\
\text { DVT. }\end{array}$ & 28 & 46 & 49 & 81 \\
\hline Q20 & $\begin{array}{l}\text { Daily physical activity can prevent DVT of bed } \\
\text { ridden patient. }\end{array}$ & 30 & 50 & 45 & 75 \\
\hline Total & & 492 & 790 & $\mathbf{9 3 1}$ & $\mathbf{1 5 4 6}$ \\
\hline
\end{tabular}

Item wise analysis of pre-test and post-test percentage score of the subject related to the knowledge aspects of staff nurse (N-60) are given in above table. Frequency and percentage of pretest score from knowledge of staff nurses is 492 and 790 respectively whereas frequency and percentage post test score is 931 and 1546 respectively.

Effectiveness of planned teaching program on DVT among staff nurses

a. Comparison between the pre-test and post-test score of knowledge aspect (N-60).

To find out the effectiveness of planned teaching program to asses the knowledge of DVT among the staff nurse, total score of knowledge aspect was collected from the pre-test and post-test. Mean score; mean score percentage and standard deviation was calculated from each test. Then the pre-test findings of mean score; mean score percentage and standard deviation was compared with the post-test findings.

Comparison between the pre-test and post-test score of knowledge aspect $(N-60)$.

\begin{tabular}{|c|c|c|c|c|c|c|c|c|}
\hline \multirow{2}{*}{ Area } & \multicolumn{4}{|c|}{ Pre-test } & \multicolumn{4}{|c|}{ Post-test } \\
\cline { 2 - 8 } & $\begin{array}{c}\text { Mean } \\
\text { score }\end{array}$ & SD & $\begin{array}{c}\text { Mean score } \\
\text { percentage }\end{array}$ & SD & $\begin{array}{c}\text { Mean } \\
\text { score }\end{array}$ & SD & $\begin{array}{c}\text { Mercentage } \\
\text { percentage }\end{array}$ & SD \\
\hline $\begin{array}{c}\text { Knowledge } \\
\text { aspect }\end{array}$ & 24.6 & 11.4 & 39.5 & 20.26 & 46.55 & 7.77 & 77.3 & 13.02 \\
\hline
\end{tabular}

Mean pretest score on knowledge of staff nurses was 24.6 \& after planned teaching programme it was 77.3 which denotes there was some increase in knowledge score after planned teaching programme.

b. Co-relation of pre-test score of knowledge aspect with the post-test knowledge aspect by using Karl Pearson's co-relation formula.

To find out the co-relation scores of knowledge aspect was obtained after pre-test. Co-relation was calculated by applying Karl Pearson's co-efficient. After that the table was compared with the calculated values.

Co-relation of pre-test score of knowledge aspect with the post-test knowledge 


\begin{tabular}{|l|l|l|l|}
\hline S.L. No. & Scores & 'r' value & Inference \\
\hline 1 & $\begin{array}{l}\text { Pre test knowledge } \\
\text { Post test knowledge }\end{array}$ & $0.14 * *$ & Significant \\
\hline
\end{tabular}

** Correlation is significant at the 0.01 level

From above the table ' $r$ ' value $(0.14)$ is found to be highly significant which shows that the co-relation among pre-test and post-test knowledge is positive.

c. Calculation of the difference between the pre-test and post-test knowledge scores by using paired ' $t$ ' test.

Difference between the pre-test and post-test knowledge

\begin{tabular}{|l|l|l|l|l|}
\hline $\begin{array}{l}\text { S.L. } \\
\text { No. }\end{array}$ & Type of Mean & Mean difference & Mean score percentage & \multirow{2}{*}{ 't' value } \\
\hline 1 & Pre-test & \multirow{2}{*}{2.6} & 39.5 & \multirow{2}{*}{$21.8 * *$} \\
& Post-test & 77.3 & \\
\hline
\end{tabular}

** Correlation is significant at the 0.01 level

There was a significant difference between the mean pre-test and post-test knowledge scores of staff nurse regarding deep vein thrombosis thus the planned teaching program is effective in increasing the knowledge on DVT among the staff nurses of IMS \& SUM Hospital.

\section{Conclusion}

The investigator observed the planned teaching programme on Deep Vein Thrombosis (DVT) by comparing mean scores, median \& standard deviation of Pre test score and Post test scores of knowledge aspect which were significantly higher. There is a significant correlation between Pre test knowledge and Post test knowledge by using Kerl Pearson's Coefficient correlation $r=0.14$ at $90 \%$ level of significance \& it was a positive correlation. The obtained ' $t$ ' value was 21.8 with a mean difference 2.6 was much greater than the tabulated value. The nurse administrator can plan and implement different education programme through laid down protocols and manuals for the people suffering from DVT and thus to ensure an overall healthy population and reduce the incidence of DVT.

\section{Reference}

[1]. Autar, R .Deep Vein Thrombosis: The Silent Killer. Quay Books. Mark Allen Publishing, Wiltshire

[2]. Anands SS, Wells PS, Hunt D, et al. (1998) Does the patient have deep vein thrombosis? Journal of the American Medical Association,279(14): 1094-1099

[3]. Tortora, G.J., \& Derrickson, B., (2006). Principles of anatomy and physiology. Hoboken, NJ: Wiley.

[4]. Turpie, AGG .(1997), Low molecular weight heparin: from the bench to the orthopaedic patients.Orthopedics (February): 10-13

[5]. Collier ,M. Anti-embolic stockings for prevention and treatment of deep vein thrombosis.Br J Nurs, 1998,(1): 44-49

[6]. Goldman, L., \& Ausiello, D. Cecil medicine (23r ed.). Philadelphia, PA: Saunders Elsevier.

[7]. Surendra, K. A prospective study of risk factor profile \& incidence of deep venous thrombosis among medically-ill hospitalized patients at a tertiary care hospital in northern India. Indian J Med Res 30 (3), 2009, ,726-730 .

[8]. Markel, A. Valvular reflux after deep vein thrombosis: incidence and time of occurrence. J.vas.nsg.1992 Feb; 15(2):377-82 